\title{
CP-25 exerts anti-angiogenic effects on a rat model of adjuvant-induced arthritis by promoting GRK2-induced downregulation of CXCR4-ERK1/2 signaling in endothelial cells
}

\author{
MIN ZHANG ${ }^{1,2}$, MEI GAO $^{1,3}$, JINYU CHEN $^{1}$, LIHUA SONG $^{1}$ and WEI WEI ${ }^{1}$ \\ ${ }^{1}$ Institute of Clinical Pharmacology, Anhui Medical University, Key Laboratory of Anti-inflammatory and Immune Medicine, \\ Ministry of Education, Anhui Collaborative Innovation Center of Anti-inflammatory and Immune Medicine, \\ Hefei, Anhui 230032; ${ }^{2}$ Department of Anesthesiology, The First Affiliated Hospital of USTC, \\ Division of Life Sciences and Medicine, University of Science and Technology of China, Hefei, Anhui 230001; \\ ${ }^{3}$ Department of Pharmacy, Anhui Chest Hospital, Hefei, Anhui 230031, P.R. China
}

Received July 29, 2018; Accepted July 4, 2019

DOI: $10.3892 / \mathrm{mmr} .2019 .10765$

\begin{abstract}
Angiogenesis can produce an invasive and destructive front, also named a pannus, comprised of inflammatory vascular tissue that covers and erodes articular cartilage, subchondral bone and peri-articular soft tissues in rheumatoid arthritis (RA). Paeoniflorin-6'-O-benzene sulfonate (CP-25) is a novel ester derivative of paeoniflorin. We previously demonstrated that CP-25 exerts anti-inflammatory and immunoregulatory effects. CP-25 also exhibits a marked therapeutic effect on adjuvant-induced arthritis (AA), and is able to inhibit synovial and immune cell function, according to our previous study. However, the effect of CP-25 on angiogenesis remains unclear. In the present study, AA was initiated in Sprague-Dawley rats via intradermal immunization in the right hind metatarsal footpad with heat-killed Mycobacterium butyricum in liquid paraffin, and rats were divided into four groups: Normal, AA rat model, CP- $25(50 \mathrm{mg} / \mathrm{kg})$ and methotrexate $(0.5 \mathrm{mg} / \mathrm{kg})$ groups ( $\mathrm{n}=10 \mathrm{rats} / \mathrm{group})$. Subsequently, joint synovium in AA rats was pathologically evaluated by hematoxylin and eosin staining, synovial vascular proliferation was evaluated by immunofluorescence, the synovial expression levels of C-X-C motif chemokine ligand 12 (CXCL12) were detected by immunohistochemistry and ELISA, and
\end{abstract}

Correspondence to: Professor Lihua Song or Professor Wei Wei, Institute of Clinical Pharmacology, Anhui Medical University, Key Laboratory of Anti-inflammatory and Immune Medicine, Ministry of Education, Anhui Collaborative Innovation Center of Anti-inflammatory and Immune Medicine, 81 Meishan Road, Hefei, Anhui 230032, P.R. China

E-mail:songlh@ankebio.com

E-mail: wwei@ahmu.edu.cn

Key words: CP-25, angiogenesis, rheumatoid arthritis, C-X-C chemokine receptor type 4-ERK1/2 signaling, human umbilical vein endothelial cells synovial C-X-C chemokine receptor type 4 (CXCR4) was detected by western blotting. The results demonstrated that CP-25 ameliorated clinical signs and pannus formation in the ankle joint in rats with AA. Furthermore, there was a positive correlation between pannus score and CXCL12 and CXCR4 expression. In addition, the effects of CP- 25 on endothelial cell function and CXCL12/CXCR4 signaling were studied in vitro using human umbilical vein endothelial cells (HUVECs). The results demonstrated that CXCL12 significantly promoted HUVEC proliferation, migration and tube formation, and that $\mathrm{CP}-25$ could reverse these abnormalities by inhibiting plasma membrane localization of $\mathrm{G}$ protein-coupled receptor kinase 2 (GRK2) in HUVECs. These findings suggested that CP-25 may markedly inhibit pannus formation in AA. This effect may be associated with a reduction in the plasma membrane localization of GRK2 in endothelial cells, an enhancement of the inhibitory effect of GRK 2 on ERK1/2 in the cytoplasm, a reduction in the phosphorylation of ERK1/2 and in the function of HUVECs.

\section{Introduction}

Rheumatoid arthritis (RA) is a chronic inflammatory disease that causes synovial hyperplasia and progressive joint degeneration (1). The characteristic histopathological features of arthritis include marked proliferation of synoviocytes, infiltration of large mononuclear cells, extensive degradation of deep cartilage and pannus formation (2). These features are also observed in a rat model of adjuvant-induced arthritis (AA) (3). Angiogenesis consists of the formation of new blood vessels from pre-existing vasculature; this process has a critical role in the pathogenesis of RA. Angiogenesis promotes the infiltration of inflammatory cells into the joints and stimulates the generation of a pannus that covers and erodes articular cartilage, subchondral bone and peri-articular soft tissues. This eventually leads to joint destruction and the deformities observed in chronic arthritis (4-6).

Chemokine C-X-C motif chemokine ligand 12 (CXCL12), also known as stromal cell-derived factor 1 , is released by 
various immune cells, endothelial cells and stem cells, and is widely expressed in the whole body under physiological conditions $(7,8)$. C-X-C-motif chemokine receptor 4 (CXCR4), which is the specific receptor for CXCL12, is expressed on various cell types, including tumor cells. CXCR4 serves a crucial role in organ-specific metastasis, where it can direct the migration of CXCR4-expressing malignant cells towards microenvironments where its ligand is secreted (9). CXCR4 is also a co-receptor for human immunodeficiency virus type 1 (10), and is highly expressed in synovial tissue and endothelial cells in RA (11). It has been reported that aberrant expression of CXCR4 causes impaired neovascularization (12) and that CXCL12 is upregulated in the synovial fluid in RA (13). Furthermore, it has been reported that CXCL12 and CXCR4 levels in the synovium are associated with clinical outcome, and with bone and joint destruction, in patients with RA treated with golimumab (14). The present study confirmed that the CXCL12/CXCR4 pathway may serve a pathogenic role via angiogenesis in RA.

The novel compound paeoniflorin (Pae)-6'-O-benzene sulfonate (CP-25; $\mathrm{C}_{29} \mathrm{H}_{32} \mathrm{O}_{13} \mathrm{~S}$; molecular weight: $620 \mathrm{~g} / \mathrm{mol}$; patent no. in China: ZL20121003061 6.4; Fig. 1A) (15) is a new ester derivative of Pae. Pae is the main effective compound in total glucosides of paeony, which is extracted from the roots of Paeonia lactiflora Pall, and is a traditional Chinese medicine that has anti-inflammatory and immunoregulatory effects (16-23). However, studies have revealed that Pae bioavailability is low (3-4\%); this phenomenon is mainly due to the poor absorption of Pae, which is partially caused by modest permeation, efflux via P-glycoprotein and hydrolytic degradation in the intestine $(24,25)$. Our previous study revealed that the oral and venous pharmacokinetic parameters of CP-25 are better than Pae (CP-25: t1/2=2.11 h, MRT=4.30 h, $\mathrm{Vd}=146.67 \mathrm{l} / \mathrm{kg}, \mathrm{CL} / \mathrm{F}=58.17 \mathrm{l} / \mathrm{h} \cdot \mathrm{kg}$; Pae: $\mathrm{t} 1 / 2=1.45 \mathrm{~h}$, $\mathrm{MRT}=3.91 \mathrm{~h}, \mathrm{Vd}=17.30 \mathrm{l} / \mathrm{kg}, \mathrm{CL} / \mathrm{F}=68.02 \mathrm{l} / \mathrm{h} \cdot \mathrm{kg}$ ) (26). In addition, $\mathrm{CP}-25$ has superior intestinal absorption compared with Pae (27). Consistent with another study (28), CP-25 can attenuate the clinical signs of AA by inhibiting the expression of pro-inflammatory cytokines, including interleukin (IL)-1 $\beta$, tumor necrosis factor (TNF)- $\alpha$, IL-6 and IL-17, and promoting the production of the anti-inflammatory cytokine TNF- $\beta 1$. In addition, a previous in vitro study reported that CP-25 attenuates the inflammatory response of fibroblast-like synoviocytes co-cultured with B cell activating factor-activated $\mathrm{CD}^{+}$ T cells (29). However, the anti-angiogenic effects of CP-25 and its underlying mechanisms remain unclear.

G protein-coupled receptor kinase 2 (GRK2) is a member of the serine/threonine protein kinases family, which has emerged as a pivotal integrative scaffold in endothelial and fibroblast cells $(30,31)$. A previous study revealed the dysfunction and overexpression of GRK2 in patients with RA and animal models of RA, which suggests that GRK2 may be considered a potential target in the treatment of RA (32). The present study hypothesized that $\mathrm{CP}-25$ may exert anti-angiogenic effects on AA and could suppress the functions of human umbilical vein endothelial cells (HUVECs) in vitro through regulation of GRK2 and the CXCL12/CXCR4 pathway. The expression levels of CXCL12 and CXCR4 were therefore examined in the synovium of rats with AA and the effects of CP-25 on HUVEC function was investigated in vitro. To the best of our knowledge, the present study is the first to demonstrate the potential therapeutic effect of CP-25 on AA and to determine the mechanism underlying its anti-angiogenic effect. The findings from this study may provide a scientific basis for the development of novel CP-25-containing drugs in the treatment of autoimmune diseases.

\section{Materials and methods}

Animals. A total of 45 Sprague-Dawley rats (male; age, 6-8 weeks; weight, 180-200 g) were purchased from the Experimentation Animal Center of Anhui Medical University. All rats were maintained in a specific pathogen-free animal laboratory $\left(20-25^{\circ} \mathrm{C}\right.$; relative humidity, 50-60\%; 12-h light/dark cycle; free access to food and water) at the Experimentation Animal Center of Anhui Medical University.

Reagents. RPMI-1640 medium and fetal bovine serum (FBS) were purchased from HyClone; GE Healthcare Life Sciences. HUVECs were purchased from All Cells BioTech Co., Ltd. Cell Counting kit-8 (CCK-8) was purchased from Dojindo Molecular Technologies, Inc. An ELISA kit for CXCL12 (cat. no. CSB-E08729r) was purchased from Cusabio, Inc. Antibodies against $\alpha$-smooth muscle actin ( $\alpha$-SMA) (cat. no. ab32575), CXCR4 (cat. no. ab124824), GRK2 (cat. no. ab228705), ERK1/2 (cat. no. ab79853), phosphorylated (p)-ERK1/2 (cat. no. ab214362), CXCL12 (cat. no. ab9797), and $\beta$-actin (cat. no. ab115777) were purchased from Abcam. The Na K-ATPase antibody (cat. no. 3010S) was purchased from Cell Signaling Technology, Inc.

Drugs. Methotrexate (MTX; $2.5 \mathrm{mg}$ per tablet) was purchased from Shanghai Xinyi Pharmaceutical Co., Ltd. CP-25 was provided by the Chemistry Lab of the Institute of Clinical Pharmacology of Anhui Medical University.

Arthritis induction and treatments. To establish a rat model of AA, $100 \mu \mathrm{l}$ (1 mg/rat) heat-killed Mycobacterium butyricum (provided by Beijing Biological Products Research Institute Co., Ltd.) in liquid paraffin was intradermally injected into the right hind metatarsal footpad, as previously described $(28,33)$. Rats were randomly divided into four groups ( $n=10 /$ group) as follows: i) Normal (no immunization); ii) AA model; iii) CP-25, AA rats treated with CP-25 (50 mg/kg); and iv) MTX, AA rats treated with MTX $(0.5 \mathrm{mg} / \mathrm{kg})$.

Our previous study demonstrated that 50 and $100 \mathrm{mg} / \mathrm{kg}$ exerted therapeutic effects on AA rats; therefore, $50 \mathrm{mg} / \mathrm{kg}$ CP-25 was used in the present study (28). Although novel biological agents can ameliorate inflammatory reactions and protect the joints of patients with rheumatoid disease from progressive damage, MTX remains one of the most effective and widely used clinical disease-modifying anti-rheumatic drugs. Previous studies have used MTX as a positive control in animal models including rats with AA and mice with collagen-induced arthritis (CIA). MTX was therefore used in the present study as a positive control drug, and the dosage of $0.5 \mathrm{mg} / \mathrm{kg}$ was determined according to previous studies $(28,29,34)$.

The day of the first immunization was defined as day 0 . AA joint inflammation in treated rats reached a maximum 
at days 13-16 following administration of the adjuvant. After the onset of arthritis on day 16, as determined based on paw swelling of the rats, rats were administered CP-25 (once per day) for 14 days and MTX (once every 3 days, five times) by intragastric administration. Normal rats and rats with AA received an equal volume of $0.9 \%$ saline.

A blinded single observer who had no knowledge of the treatment groups evaluated AA severity. From day 7 following immunization, rats were examined every 3 days for paw volume and body weight. Footpad volume was measured using a water plethysmometer.

Histological examination. Rats were anesthetized and sacrificed on day 30 after immunization. The left ankle joints were removed, fixed in $10 \%$ neutral-buffered formalin for 2 weeks at $25^{\circ} \mathrm{C}$, decalcified in $10 \%$ ethylenediaminetetracetic acid for 3 months at $25^{\circ} \mathrm{C}$ and embedded in paraffin. The sections $(5 \mu \mathrm{m})$ were stained with $0.2 \%$ hematoxylin for $10 \mathrm{~min}$ and $0.5 \%$ eosin for $10 \mathrm{sec}$ at $25^{\circ} \mathrm{C}$ and were examined under a fluorescence microscope (80I; Nikon Corporation). Ankle joints were histopathologically analyzed for inflammation, synovial proliferation, cellular infiltration, pannus formation and cartilage erosion by two blinded observers.

The expression of CXCL12 was detected by immunohistochemical staining and was examined by a fluorescence microscope. The 5- $\mu \mathrm{m}$ paraffin-embedded joint sections were processed using a standard immunostaining protocol. Initially, sections were deparaffinized in $100 \%$ xylene for $15 \mathrm{~min}$ and hydrated in a descending series of alchol at room temperature. Subsequently, sections were heated at $100^{\circ} \mathrm{C}$ for $15 \mathrm{~min}$ in $0.01 \mathrm{~mol} / 1$ citric acid buffer $(\mathrm{pH} \mathrm{6.0)}$ in a microwave oven for antigen retrieval and were then treated with $3 \% \mathrm{H}_{2} \mathrm{O}_{2}$ for $30 \mathrm{~min}$ at $37^{\circ} \mathrm{C}$. Sections were incubated with primary antibodies against CXCL12 (1:100) overnight at $4^{\circ} \mathrm{C}$. Sections were then washed in PBS and incubated with horseradish peroxidase (HRP)-conjugated secondary antibodies (50 $\mu$; cat. no. PV-9000; OriGene Technologies, Inc.) at $37^{\circ} \mathrm{C}$ for $30 \mathrm{~min}$. Subsequently, immunostaining was observed using 3,3-diaminobenzidine (DAB) (1:20; cat. no. ZLI-9017; OriGene Technologies, Inc.) for $2 \mathrm{~min}$ and counterstaining was performed using $0.2 \%$ hematoxylin for $3 \mathrm{~min}$ at $25^{\circ} \mathrm{C}$.

Vessel formation was observed via anti- $\alpha$-SMA immunofluorescence to determine the extent of pannus formation Following deparaffinization and hydration, the joint sections were heated at $100^{\circ} \mathrm{C}$ for $15 \mathrm{~min}$ in a $0.01 \mathrm{~mol} / \mathrm{l}$ citric acid buffer $(\mathrm{pH} 6.0)$ in a microwave oven and blocked with goat serum (cat. no. ZLI-9022; OriGene Technologies, Inc.) at $37^{\circ} \mathrm{C}$ for $30 \mathrm{~min}$. Sections were incubated with rabbit anti-rat primary antibody against $\alpha$-SMA (1:100; cat. no. ab32575; Abcam) overnight at $4^{\circ} \mathrm{C}$, and incubated with TRITC-conjugated goat anti-rabbit IgG secondary antibody, (1:100; cat. no. BA1090; Wuhan Boster Biological Technology, Ltd.) at $37^{\circ} \mathrm{C}$ for $1 \mathrm{~h}$ in the dark. Tissue sections were washed three times with PBS after each step.

Pathological evaluations were performed randomly by a blinded pathologist who had no knowledge of the treatment groups. The optical density values of CXCL12 protein staining in the synovium and synovial vessel walls were acquired from five different fields of view at high power magnification (x400). All results were transformed to data using Image ProPlus 6.0 software (Media Cybernetics, Inc.). Inflammatory scoring of synovial tissue was assessed according to the following criteria: i) 0 , normal; ii) 1 , minimal inflammatory infiltration; iii) 2 , moderate infiltration with moderate edema; and iv) 3, marked infiltration with marked edema. Pannus scores were defined as synovial tissue intimately invading bone and/or cartilage and was scored from 0 to 3 as follows: i) 0 , none; ii) 1 , minimal; iii) 2 , moderate; and iv) 3 , severe.

CXCL12 detection. Synovial tissue (0.15 g) was collected, mixed with $100 \mu 1 \mathrm{PBS}$, fully ground and centrifuged at $10,956 \mathrm{x} \mathrm{g}$ for $15 \mathrm{~min}$. The supernatant was collected and reserved at $37^{\circ} \mathrm{C}$. CXCL12 concentrations were subsequently measured in the synovium using ELISA kit according to the manufacturer's protocol.

HUVEC proliferation, Transwell migration and tube formation assays. HUVECs were cultured in RPMI-1640 containing $20 \% \mathrm{FBS}, 100 \mu \mathrm{g} / \mathrm{ml}$ streptomycin and $100 \mathrm{U} / \mathrm{ml}$ penicillin at $37^{\circ} \mathrm{C}$ in a humidified incubator containing $5 \% \mathrm{CO}_{2}$. Cells were harvested and collected in the logarithmic phase, and were seeded into 96 -well plates at a density of $1 \times 10^{5}$ cells/well and in triplicate for each group. Cells were cultured with fresh medium containing CXCL12 (cat. no. ab9798; $50 \mathrm{ng} / \mathrm{ml}$; Abcam) alone or in combination with CP-25 at the specified concentrations $\left(1 \times 10^{-9}, 1 \times 10^{-8}, 1 \times 10^{-7}, 1 \times 10^{-6}\right.$ and $\left.1 \times 10^{-5} \mathrm{~mol} / \mathrm{l}\right)$. After treatment at $37^{\circ} \mathrm{C}$ for $48 \mathrm{~h}, 10 \mu \mathrm{l} \mathrm{CCK}-8$ reagent was added to each well, and the plates were incubated at $37^{\circ} \mathrm{C}$ for $1 \mathrm{~h}$. Absorbance was read using an Infinite M1000 PRO microplate reader at $450 \mathrm{~nm}$ (Tecan Group, Ltd.).

A cell migration assay was performed using Transwell culture chambers ( 24 wells; $8-\mu \mathrm{m}$ pore size; Costar; Corning Inc.). Cells were seeded at $1 \times 105$ cells/well in $100 \mu 1$ serum-free Dulbecco's modified Eagle's medium (DMEM; cat. no. PYG0074; Wuhan Boster Biological Technology, Ltd.) containing CXCL12 alone or in combination with CP-25 at the specified concentrations. After incubation at $37^{\circ} \mathrm{C}$ for $24 \mathrm{~h}$, cells that migrated to the bottom chamber were stained with $0.1 \%$ crystal violet at $37^{\circ} \mathrm{C}$ for $15 \mathrm{~min}$. After air-drying, migrated cells in each chamber were counted under a light microscope (magnification, x200; BX53; Olympus Corporation). These experiments were performed independently three times.

Prior to the tube formation assay, HUVECs were treated with CXCL12 with or without CP-25 for $24 \mathrm{~h}$. Cells were then washed with PBS, harvested and seeded in 96-well plates coated with Matrigel (BD Bioscience) at a density of $2 \times 10^{4}$ cells/well in DMEM containing $20 \% \mathrm{FBS}$ for $6 \mathrm{~h}$ at $37^{\circ} \mathrm{C}$. Images of tube formation were captured using a 1 X71 Olympus microscope (Olympus Corporation), and branch point quantifications were assessed using Image Pro Plus 6.0 software (Media Cybernetics, Inc.).

Western blotting. Synovium was homogenized in ice-cold RIPA lysis buffer (cat. no. P0013C; Beyotime Institute of Biotechnology) with a homogenizer. Samples were centrifuged at $10,956 \mathrm{x} \mathrm{g}$ for $20 \mathrm{~min}$ at $4^{\circ} \mathrm{C}$ and supernatants were collected. Furthermore, proteins were extracted from HUVECs using RIPA lysis buffer. Protein concentration was determined using the Bradford assay. Equal amounts of protein samples were mixed with $5 \mathrm{X}$ sample buffer $(4: 1)$ 
(Bio-Rad Laboratories, Inc.) and heated in boiling water for $10 \mathrm{~min}$. Proteins $(20 \mu \mathrm{l} ; 10 \mu \mathrm{g} / \mu \mathrm{l})$ were then separated by $12 \%$ SDS-PAGE and transferred onto polyvinylidene fluoride membranes (EMD Millipore). Membranes were blocked for $1 \mathrm{~h}$ at room temperature in 5\% skimmed milk and incubated overnight at $4^{\circ} \mathrm{C}$ with primary antibodies against CXCR4 (1:1,000; cat. no. ab124824; Abcam) and GRK2 (1:1000; cat. no. ab228705; Abcam). Membranes were washed with Tris-buffered saline containing $0.05 \%$ Tween-20 (TBST) three times for $10 \mathrm{~min}$ and were then incubated with HRP-conjugated secondary antibodies (1:10,000; cat. no. ab205718; Abcam). for $2 \mathrm{~h}$ at room temperature. Membranes were washed three times with TBST and bands were detected using enhanced chemiluminescence substrate (Pierce; Thermo Fisher Scientific, Inc.). Autoradiographs were scanned using an ImageQuant LAS 4000 mini-system (GE Healthcare Life Sciences). Relative expression levels of the specific bands were quantified using ImageJ software 1.8.0 (National Institutes of Health).

In addition, HUVECs were treated with CXCL12 for $30 \mathrm{~min}$ and with CP-25 at the specified concentrations for $24 \mathrm{~h}$. Cells were then lysed in RIPA lysis buffer and the total proteins were collected following centrifugation at $10,956 \mathrm{x} \mathrm{g}$ for $10 \mathrm{~min}$ at $4^{\circ} \mathrm{C}$. Membrane and cytoplasmic proteins were separated from total proteins using a cell membrane protein and cytoplasmic protein extraction kit (cat. no. P0033; Beyotime Institute of Biotechnology) by ultracentrifugation at $559,000 \mathrm{x} \mathrm{g}$ for $60 \mathrm{~min}$ at $4^{\circ} \mathrm{C}$. The protein fractions then underwent western blotting as aforementioned. The primary antibodies used included ant-CXCR4, anti-GRK2, anti-ERK1/2 and anti-p-ERK1/2 (1:1,000). The secondary antibody used was a HRP-conjugated secondary antibody (1:10,000; cat. no. ab205718; Abcam).

Co-immunoprecipitation. The co-expression of GRK2 with CXCR4 and p-ERK1/2 was analyzed by co-immunoprecipitation. HUVECs were divided into three groups as follows: i) Control group (untreated HUVECs); ii) CXCL12 group (HUVECs treated with $100 \mathrm{ng} / \mathrm{ml} \mathrm{CXCL12} \mathrm{for} 30 \mathrm{~min}$ at $37^{\circ} \mathrm{C}$ ); and iii) CP-25 group (HUVECs treated with $100 \mathrm{ng} / \mathrm{ml}$ CXCL12 for $30 \mathrm{~min}$ and with $1 \times 10^{-6} \mathrm{~mol} / 1 \mathrm{CP}-25$ for $24 \mathrm{~h}$ at $37^{\circ} \mathrm{C}$ ). Subsequently, cells were lysed in RIPA lysis buffer and total proteins were collected following centrifugation at $10,956 \mathrm{x} \mathrm{g}$ for $10 \mathrm{~min}$ at $4^{\circ} \mathrm{C}$. A supernatant $(20 \mu \mathrm{l})$ was taken as the input fraction and the remainder was frozen at $-80^{\circ} \mathrm{C}$ prior to use. The GRK2 protein in the control group served as control for co-immunoprecipitation. Briefly, $10 \mu \mathrm{l}$ antibodies (anti-CXCR4, anti-GRK2, anti-p-ERK; 1:1,000) were conjugated to $50 \mu \mathrm{l}$ protein $\mathrm{G}$ agarose (cat. no. P2053; Beyotime Institute of Biotechnology) and diluted with RIPA lysis buffer to a volume of $500 \mu \mathrm{l}$. The mixture was shaken slowly for $2 \mathrm{~h}$ at $4^{\circ} \mathrm{C}$, and was incubated overnight at $4^{\circ} \mathrm{C}$ following centrifugation at $56 \mathrm{x} \mathrm{g}$ for $5 \mathrm{~min}$ at $4^{\circ} \mathrm{C}$. Subsequently, the sample was centrifuged at $56 \mathrm{x}$ g for $2 \mathrm{~min}$ at $4^{\circ} \mathrm{C}$. The supernatant was discarded and the pellet at the bottom of the tube was centrifuged again with $500 \mu \mathrm{l}$ RIPA lysis buffer at $56 \mathrm{x} \mathrm{g}$ for $2 \mathrm{~min}$ at $4^{\circ} \mathrm{C}$. Proteins were eventually evaluated by western blotting as aforementioned. The expression of GRK2 was used as a loading control and the relative expression levels of the specific bands were semi-quantified using ImageJ software 1.8.0 (National Institutes of Health).
Statistical analysis. Data are expressed as the means \pm standard deviation. Each experiment was repeated at least three times independently. Statistical analysis was performed using SPSS 16.0 for Windows (SPSS, Inc.). Statistical differences among groups were analyzed by one-way analysis of variance and pairwise comparisons were performed using the Bonferroni test. Spearman correlation was used for correlation analysis of two variables. $\mathrm{P}<0.05$ was considered to indicate a statistically significant difference.

\section{Results}

$C P-25$ attenuates the clinical signs and pannus formation in the ankle joint of rats with AA. The effect of CP-25 was evaluated using a murine AA model. Arthritis developed rapidly in rats following a single injection of Mycobacterium butyricum. By day 17-29 following immunization, paw swelling in the AA group had increased compared with that in the normal group. By day 20-29 following immunization, paw swelling was significantly reduced in the MTX and CP-25 groups compared with that in the AA group (Fig. 1B). CP-25 and MTX treatments therefore resulted in a significant decrease in paw volume. By day 17-29 following immunization, body weight in the AA, CP-25 and MTX groups was lower than that in the normal group (AA group, $12.5 \pm 2.5 \%$; CP-25 group, $8.8 \pm 1.0 \%$; MTX group, $12.1 \pm 1.8 \%$; average of five time points). By day 26-29 following immunization, body weight in the CP-25 group was increased compared with in the AA group, whereas MTX caused a substantial reduction in body weight (Fig. 1C).

The typical characteristics of RA include synovial hyperplasia and progressive joint destruction. Rats with AA developed severe arthritis, which was characterized by marked synovial proliferation, pannus formation and infiltration of inflammatory cells. Histopathological examination of the ankle joints revealed that there were marked differences in cell proliferation and inflammatory infiltration at the synovial margin among the four groups, and the inflammatory scores of synovial tissue in the CP-25 or MTX groups were significantly lower than in the AA group (Fig. 1D and F). Compared with in the AA group, the number of blood vessels and pannus score of synovial tissue was significantly reduced in rats with AA following administration of CP-25 and MTX (Fig. 1E and G).

CP-25 alters the expression of CXCL12/CXCR4 in the synovium of rats with $A A$. Immunohistochemistry was performed to detect the expression of CXCL12 in synovium and in the wall of blood vessels in the synovium. The results demonstrated that the expression of CXCL12 in the AA group was increased compared with in rats in the normal group. Compared with in the AA group, CXCL12 was markedly decreased in rats treated with CP-25 (Fig. 2A and B). Furthermore, the optical density value of CXCL12 was consistent with the immunohistochemical results (Fig. 2C and D). As presented in Fig. 2, CXCL12 and CXCR4 expression was increased in synovial tissues from the AA group compared with in those from the normal group. Compared with in the AA group, CXCL12 and CXCR4 expression was significantly decreased in CP-25 and MTX-treated rats (Fig. 2E and F). In addition, there was a positive correlation between pannus score and CXCL12 and CXCR4 expression (Fig. 2G and H). 
A

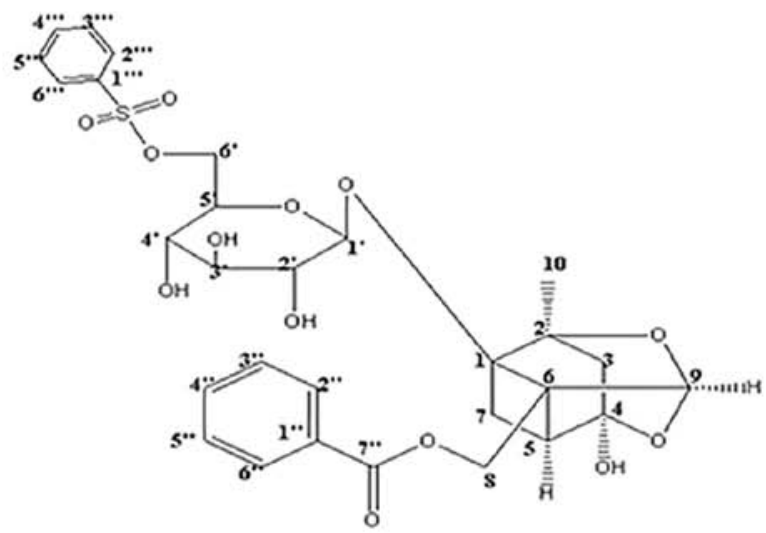

B

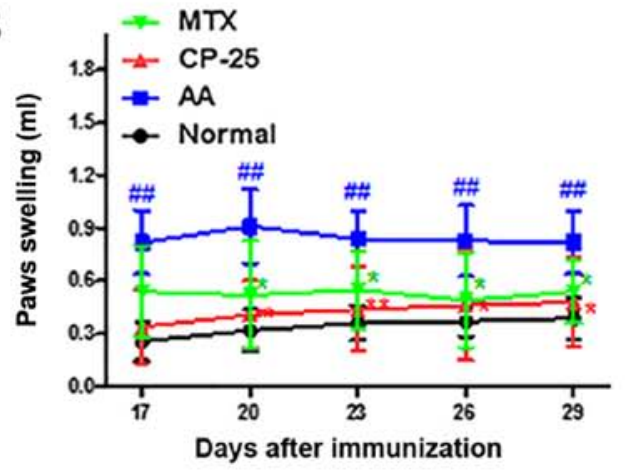

D

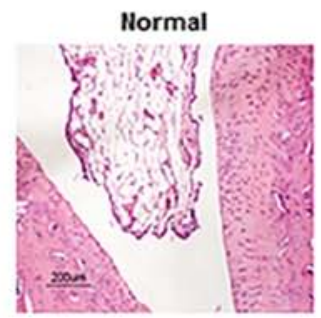

$\mathbf{E}$
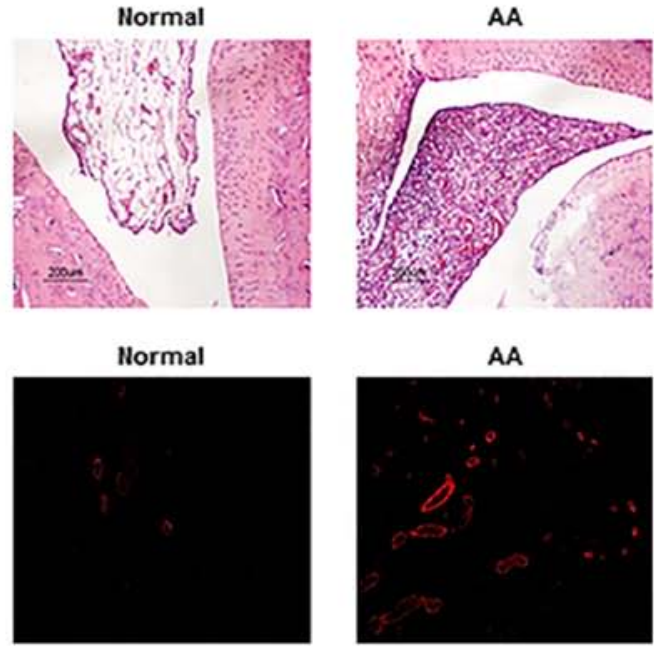

AA

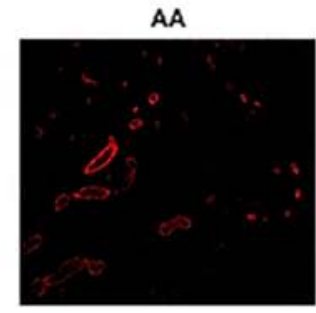

F

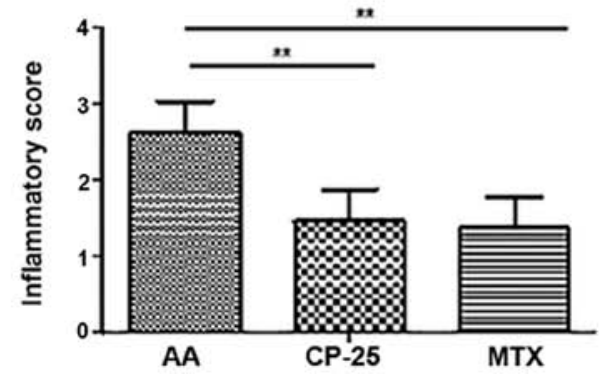

C ${ }_{400} \rightarrow \mathrm{MTX}$
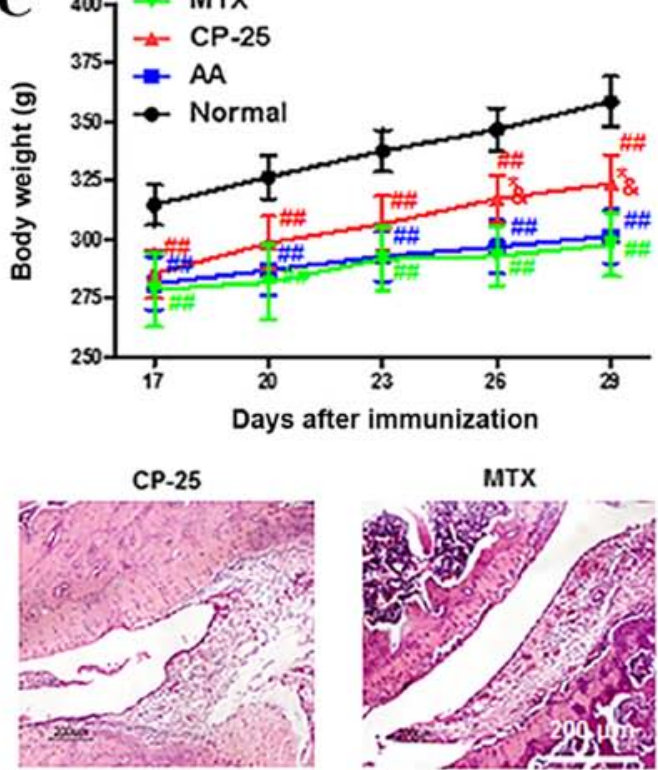

CP-25
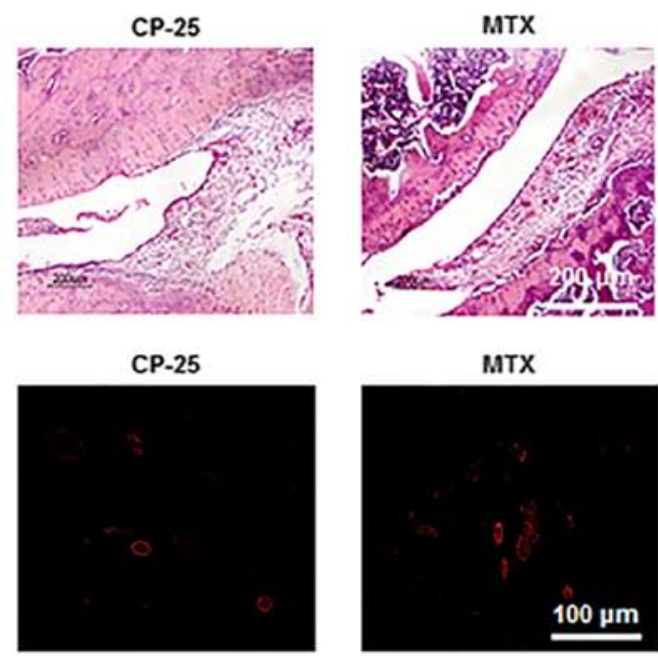

MTX
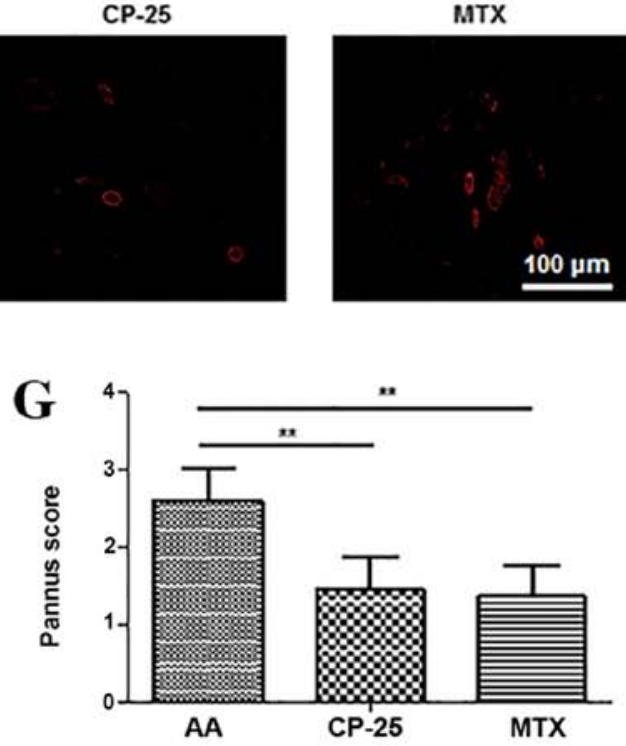

Figure 1. (A) Structure of CP-25. (B) Swelling of the non-injected hind paw and (C) body weights of rats in each group were assessed at 3-day intervals (days 17, 20, 23, 26 and 29). (D) Representative histological changes of hematoxylin and eosin-stained sections of the joints (magnification, x100). (E) Representative micrographs of pannus formation in synovial tissue assessed by immunofluorescence (original magnification, $\mathrm{x} 200$ ). (F) Inflammatory and (G) pannus scores of synovial tissue ( $>10$ microscopic fields were observed in each section). ${ }^{\# \#} \mathrm{P}<0.01$ vs. normal; ${ }^{*} \mathrm{P}<0.05,{ }^{* *} \mathrm{P}<0.01$ vs. AA group; ${ }^{\star} \mathrm{P}<0.05$ vs. MTX group ( $\mathrm{n}=10$ / group). AA, adjuvant-induced arthritis; CP-25, paeoniflorin-6'-O-benzene sulfonate; MTX, methotrexate.

These results indicated that $\mathrm{CP}-25$ inhibited pannus formation in the synovium of rats with AA, which may be associated with downregulation of CXCL12/CXCR4 expression in the synovium. 
A

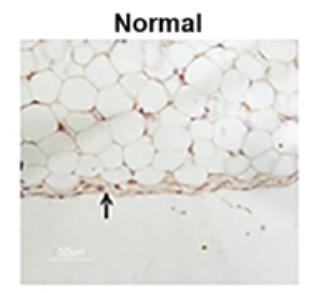

B

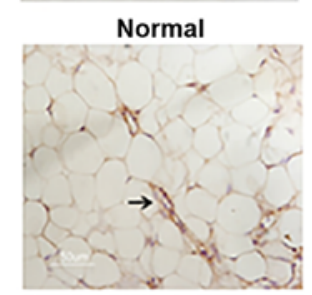

C

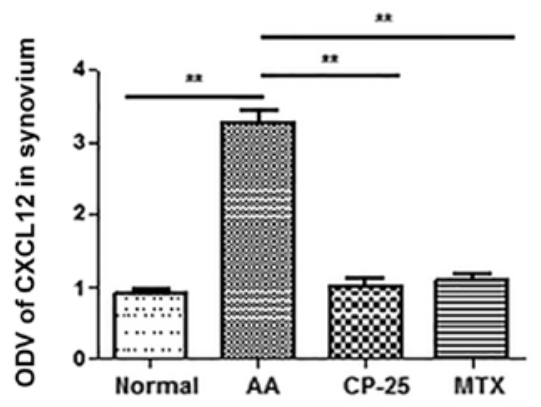

$\mathbf{E}$
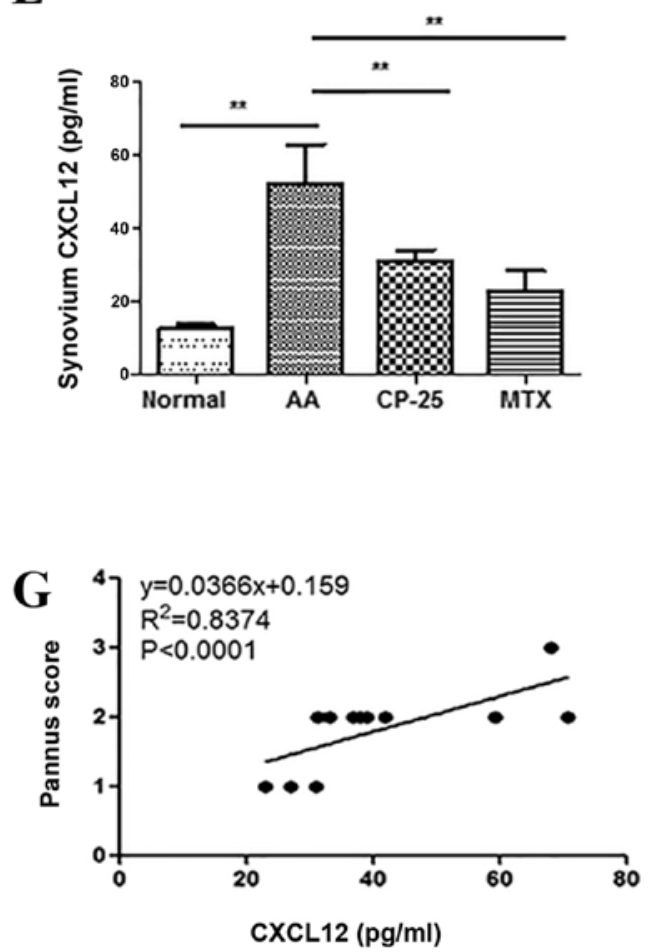

AA
CP-25
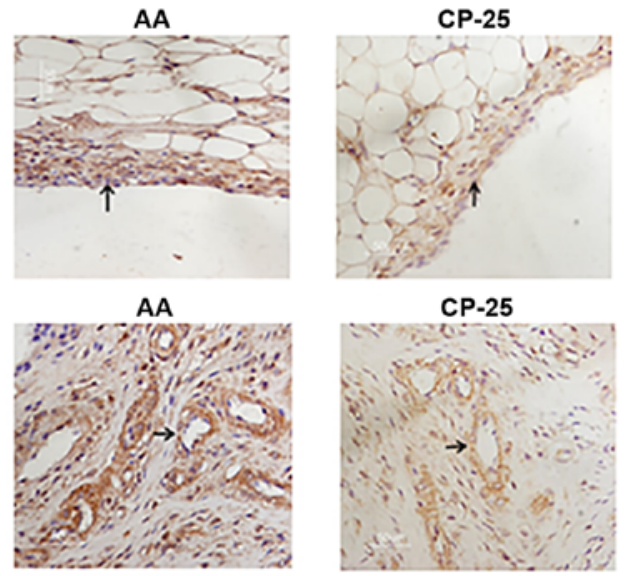

CP-25
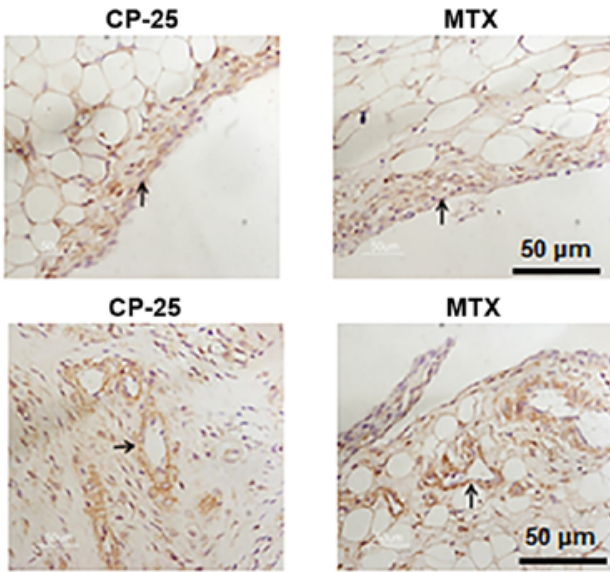

MTX

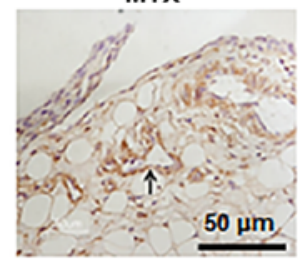

D
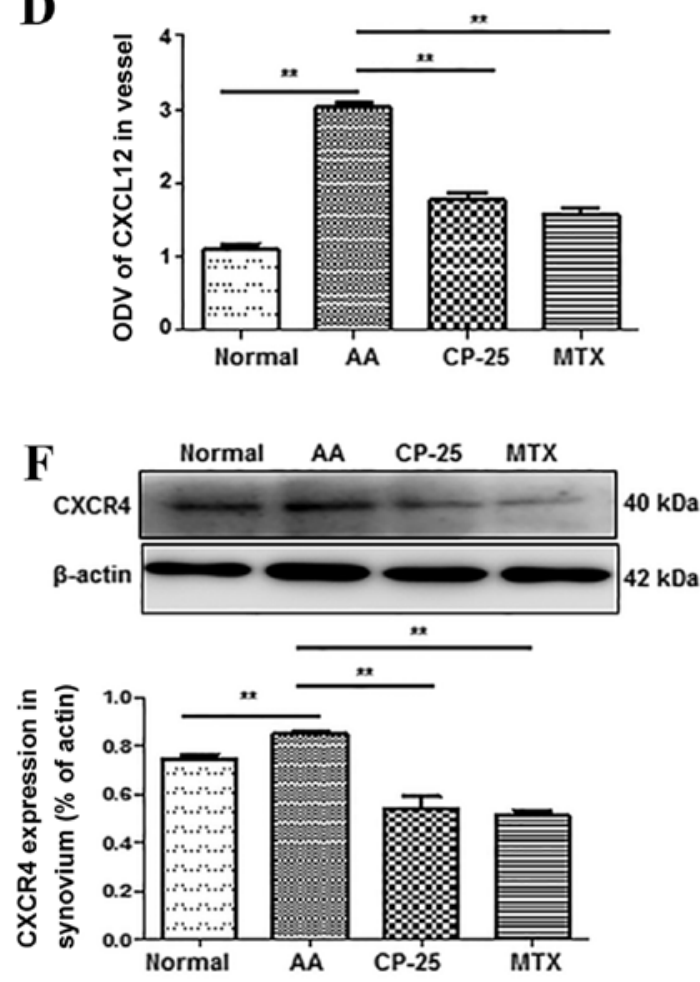

$\mathbf{H}$

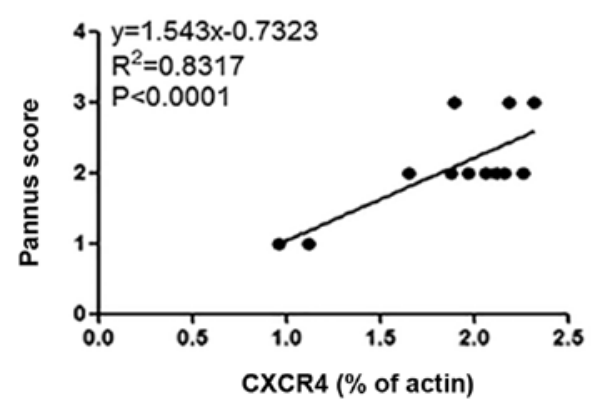

Figure 2. Expression of CXCL12 level in the synovium and the wall of blood vessel from rats. Representative immunohistochemical analyses of CXCL12 expression in the (A) synovium and (B) blood vessel walls, illustrating alterations in the joints of each group of rats (magnification, $\mathrm{x} 400$ ). ODVs of CXCL12 in the (C) synovium and (D) vessel were markedly decreased in rats with AA following administration of CP- 25 and MTX ( $>10$ microscopic fields were observed in each section). (E) Levels of CXCL12 in the synovium assessed by ELISA. (F) Representative western blotting demonstrating CXCR4 expression in rat synovium. Western blotting data are expressed as the means \pm standard deviation of three independent experiments. ${ }^{* *} \mathrm{P}<0.01$ vs. AA group ( $\mathrm{n}=8-10$ per group). $(\mathrm{G}$ and $\mathrm{H})$ Correlation between pathological alterations in the pannus score and the expression of CXCL12 and CXCR4 in synovium. AA, adjuvant-induced arthritis; CP-25, paeoniflorin-6'-O-benzene sulfonate; CXCL12, C-X-C motif chemokine ligand 12; CXCR4, C-X-C chemokine receptor type 4; MTX, methotrexate; ODV, optical density value.

Effects of CP-25 on proliferation, migration and tube formation of HUVECs treated with CXCL12. CCK-8, Transwell and tube formation assays were used to examine HUVEC proliferation, migration and tube formation, respectively. Cells were 

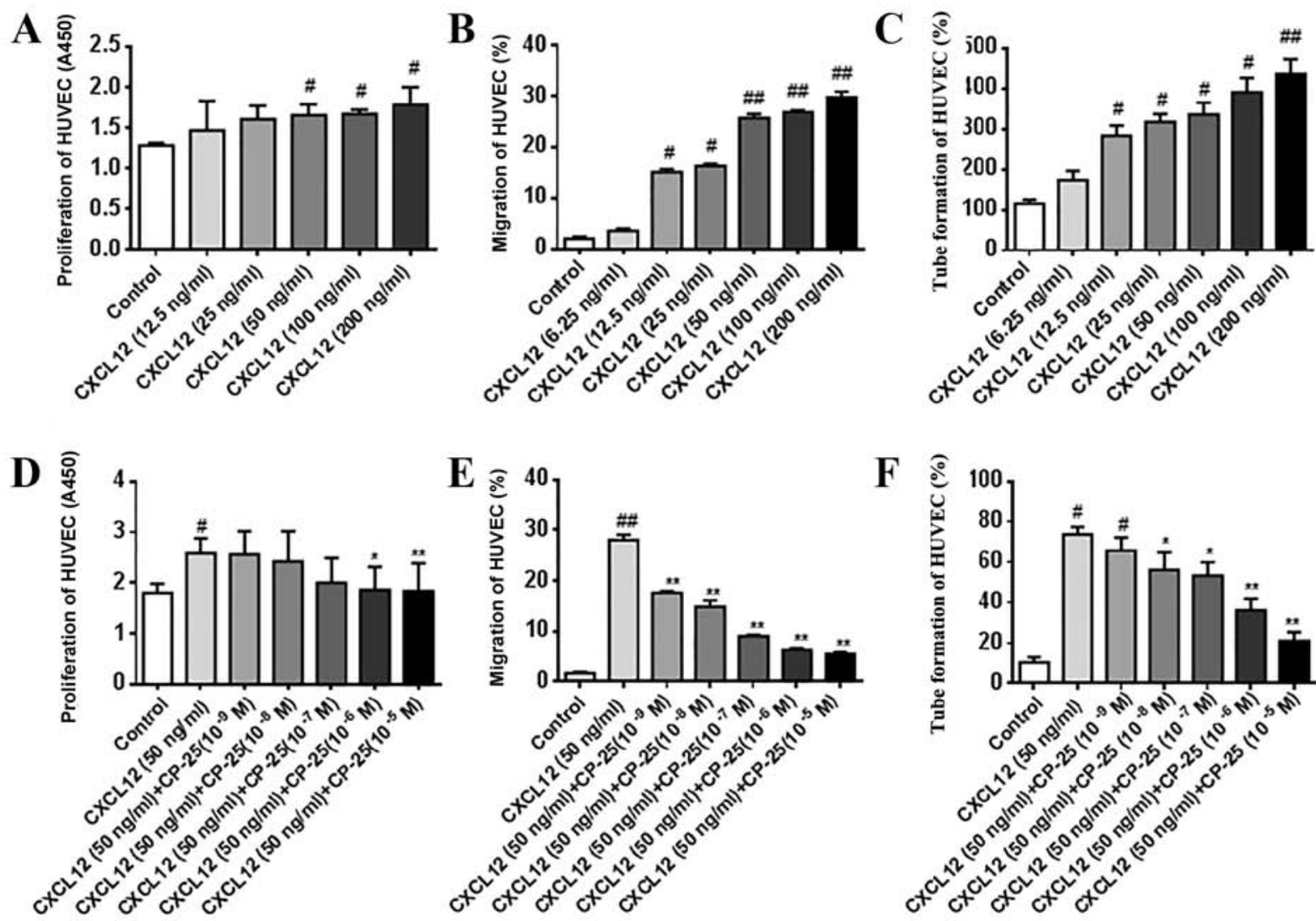

G
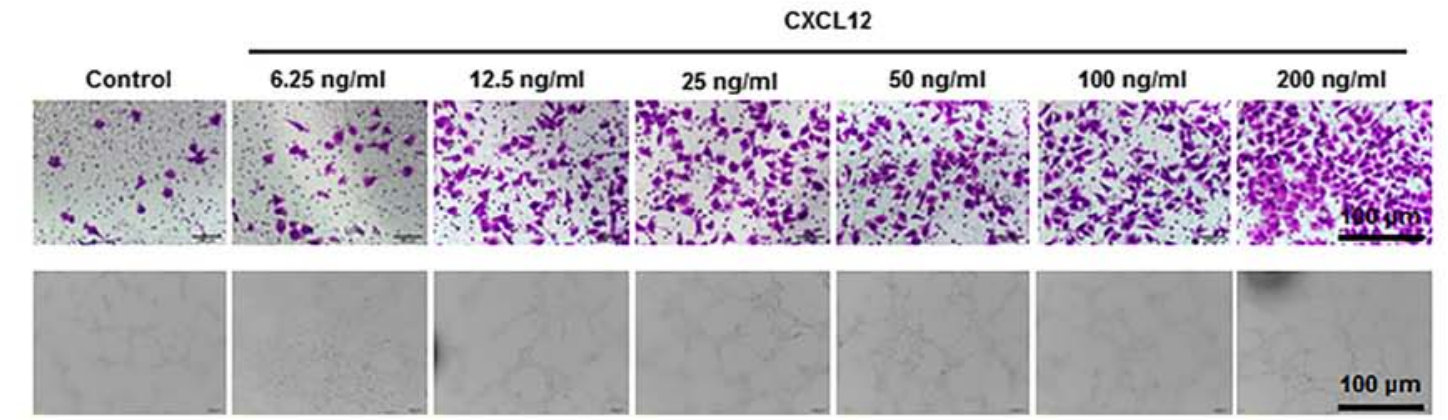

$\mathbf{H}$

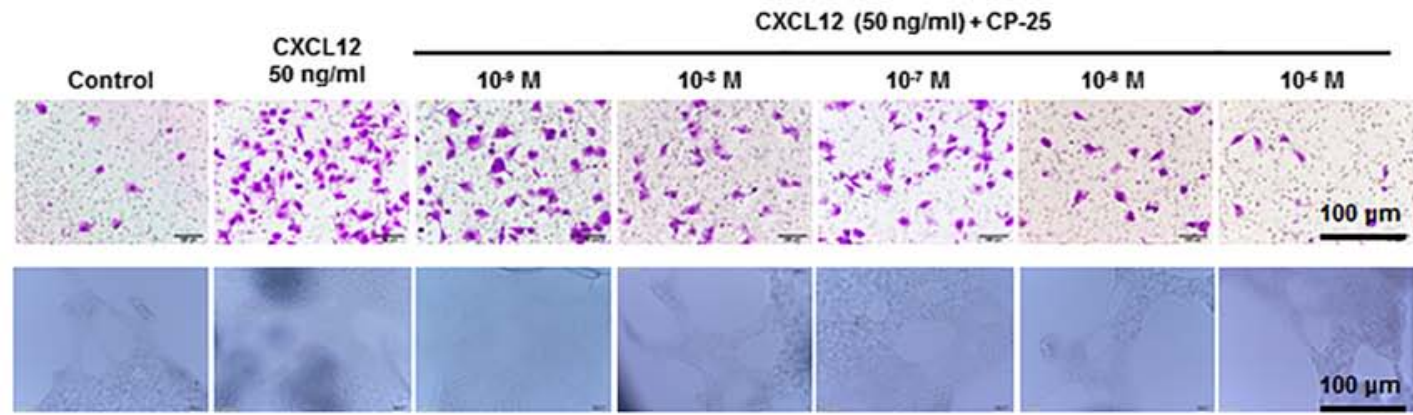

Figure 3. Effects of CP-25 on CXCL12-induced HUVEC proliferation, migration and tube formation. (A-C) Quantitative analysis of HUVEC proliferation, migration and tube formation induced by various concentrations of CXCL12 for $24 \mathrm{~h}$. (D-F) Quantitative analysis of HUVEC proliferation, migration and tube formation following treatment with CXCL12 alone or in combination with CP-25 for $24 \mathrm{~h}$. (G and H) Representative images of the Transwell and tube formation assays of HUVECs (magnification, $\mathrm{x} 200$ ). Data are expressed as the means \pm standard deviation of three independent experiments. ${ }^{\#} \mathrm{P}<0.05$, ${ }^{\# \#} \mathrm{P}<0.01$ vs. control; ${ }^{*} \mathrm{P}<0.05,{ }^{* *} \mathrm{P}<0.01$ vs. CXCL12. CP-25, paeoniflorin-6'-O-benzene sulfonate; CXCL12, C-X-C motif chemokine ligand 12; CXCR4, C-X-C chemokine receptor type 4 .

incubated with various concentrations of CXCL12 for $24 \mathrm{~h}$. The results demonstrated that treatment with high concentrations of CXCL12 (50, 100 and $200 \mathrm{ng} / \mathrm{ml})$ significantly promoted HUVEC proliferation (Fig. 3A). In addition, 12.5, 25, 50, 100 and $200 \mathrm{ng} / \mathrm{ml}$ CXCL12 significantly promoted the migration and tube formation of HUVECs (Fig. 3B, C and G). HUVECs were then treated with $50 \mathrm{ng} / \mathrm{ml} \mathrm{CXCL12} \mathrm{alone} \mathrm{or} \mathrm{in} \mathrm{combina-}$ tion with increasing concentrations of CP- $25\left(1 \times 10^{-9}, 1 \times 10^{-8}\right.$, 
A

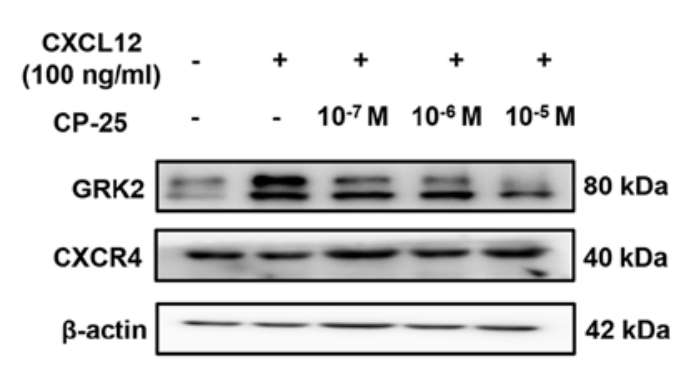

D

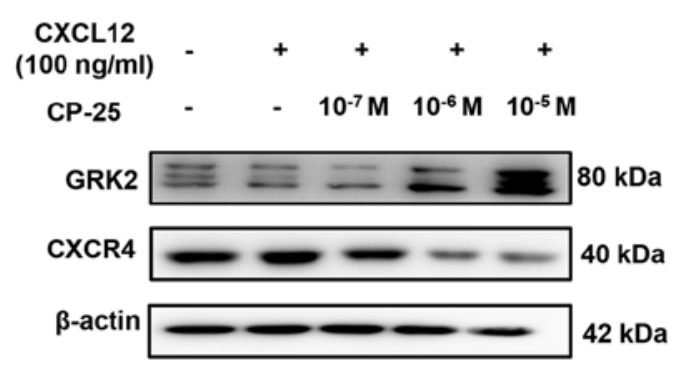

G

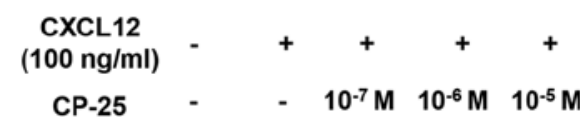

GRK2

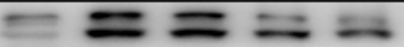

CXCR4

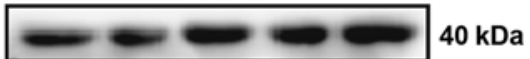

Na K-ATPase
B

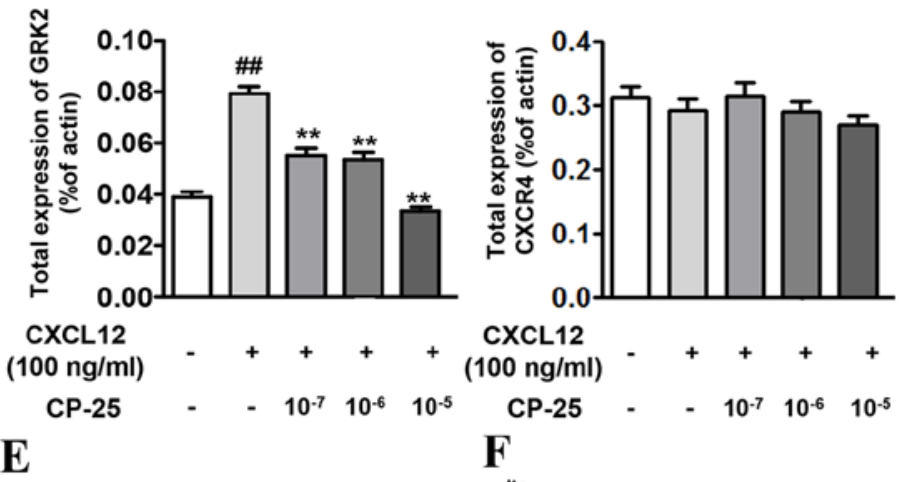

E

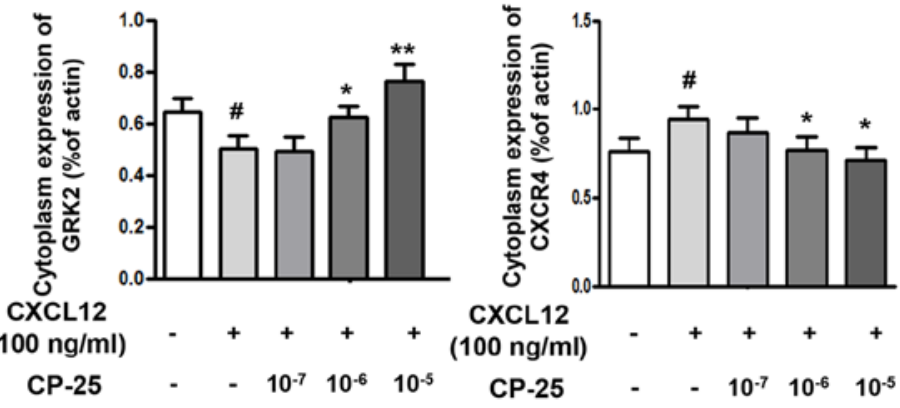

H

I

$113 \mathrm{kDa}$
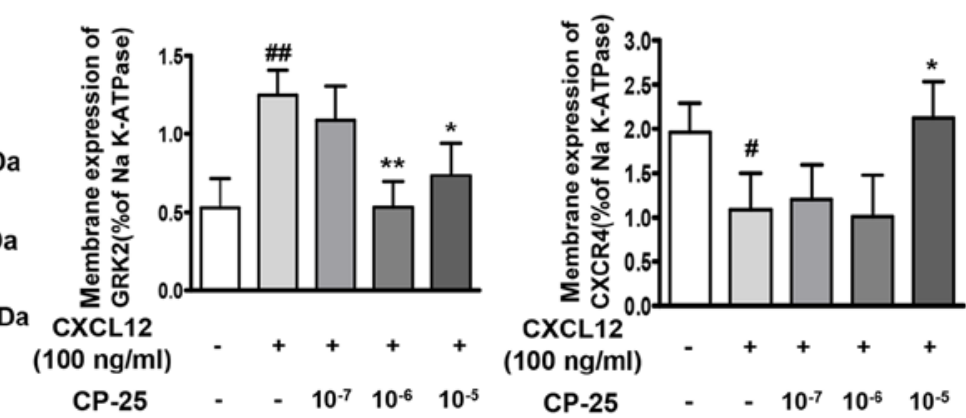

Figure 4. Effects of CP-25 on GRK2 and CXCR4 expression in HUVECs treated with CXCL12. Representative images of western blotting of (A) total, (D) cytoplasmic and (G) membrane expression of GRK2 and CXCR4. (B, C, E, F, H and I) Western blotting semi-quantification of GRK2 and CXCR4 expression. Data are expressed as the means \pm standard deviation of three independent experiments. ${ }^{\#} \mathrm{P}<0.05,{ }^{\# \#} \mathrm{P}<0.01$ vs. control; ${ }^{*} \mathrm{P}<0.05$, ${ }^{* *} \mathrm{P}<0.01$ vs. CXCL12. CP-25, paeoniflorin-6'-O-benzene sulfonate; CXCL12, C-X-C motif chemokine ligand 12; CXCR4, C-X-C chemokine receptor type 4; GRK2; G protein-coupled receptor kinase 2 .

$1 \times 10^{-7}, 1 \times 10^{-6}$ and $\left.1 \times 10^{-5} \mathrm{~mol} / \mathrm{l}\right)$ for $24 \mathrm{~h}$. The results revealed that CP-25 significantly inhibited CXCL12-induced cell proliferation (at $1 \times 10^{-6}$ and $1 \times 10^{-5} \mathrm{~mol} / \mathrm{l}$ ), migration (at $1 \times 10^{-9}, 1 \times 10^{-8}$, $1 \times 10^{-7}, 1 \times 10-6$ and $\left.1 \times 10^{-5} \mathrm{~mol} / \mathrm{l}\right)$ and tube formation (at $1 \times 10^{-8}$, $1 \times 10^{-7}, 1 \times 10^{-6}$ and $1 \times 10^{-5} \mathrm{~mol} / \mathrm{l}$ ) (Fig. 3D-F and H).

Effects of CP-25 on GRK2 and CXCR4 expression in HUVECs treated with CXCL12. Western blotting was performed to measure the expression of GRK2 and CXCR4 in HUVECs treated with $100 \mathrm{ng} / \mathrm{ml} \mathrm{CXCL12.} \mathrm{The} \mathrm{results} \mathrm{demonstrated}$ that GRK2 expression in cells treated with CXCL12 was significantly upregulated compared with that in the control group. Compared with in CXCL12-treated cells, GRK2 expression in cells treated with CP-25 $\left(1 \times 10^{-7}, 1 \times 10^{-6}\right.$ and $1 \times 10^{-5} \mathrm{~mol} / \mathrm{l}$ ) and CXCL12 was significantly downregulated. Notably, CXCR4 expression was not significantly altered by CXCL12 or CP-25 treatments (Fig. 4A-C). Furthermore, the cytoplasmic expression of GRK2 in CXCL12-treated cells was significantly downregulated compared with that in the control group. Compared with in the CXCL12-treated group, the cytoplasmic expression of GRK2 was significantly upregulated in cells treated with CP-25 (1x10 $10^{-6}$ and $\left.1 \times 10^{-5} \mathrm{~mol} / \mathrm{l}\right)$. Conversely, CXCR4 expression was significantly downregulated in the cytoplasm in response to CP-25 $\left(1 \times 10^{-6}\right.$ and $1 \times 10^{-5} \mathrm{~mol} / \mathrm{l}$ ) (Fig. 4D-F). The membrane expression of GRK2 in cells treated with CXCL12 was significantly upregulated compared with that in the control cells. Compared with CXCL12 treatment, the membrane expression of GRK 2 in cells

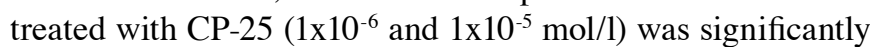
reduced. The expression of CXCR4 was significantly upregulated in cells treated with CP-25 $\left(1 \times 10^{-5} \mathrm{~mol} / \mathrm{l}\right)$ (Fig. 4G-I).

Effects of CP-25 on ERK1/2 expression in HUVECs treated with CXCL12. As presented in Fig. 5, there was no difference in ERK1/2 expression among the treatment groups. However, the expression of $\mathrm{p}$-ERK $1 / 2$ and the ratio of $\mathrm{p}$-ERK/ERK in CXCL12-treated cells were significantly upregulated compared with those in the control group. Compared with in 

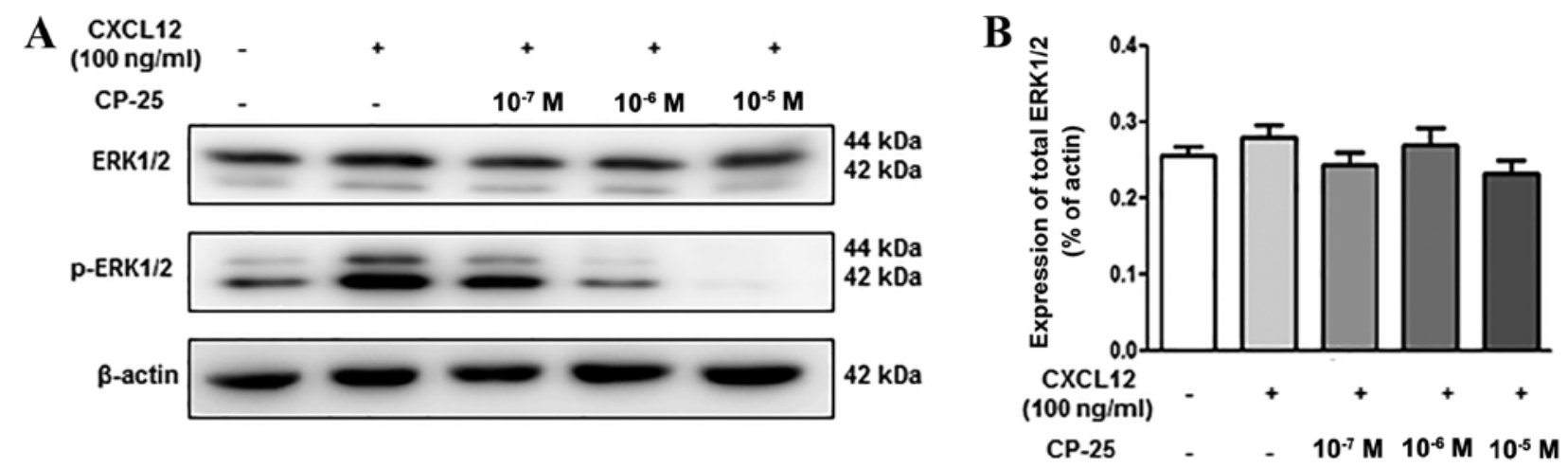

C

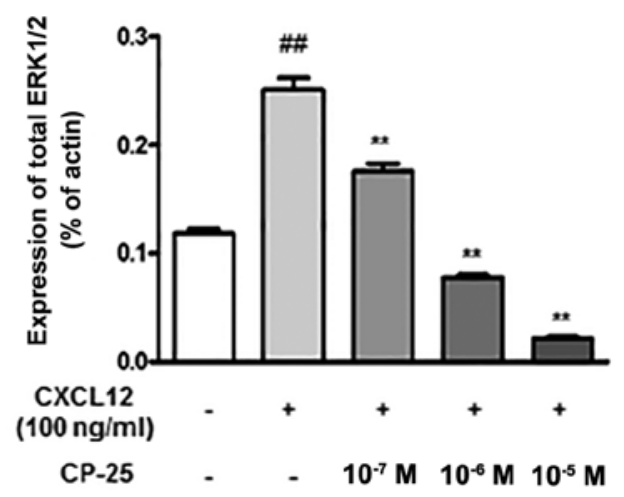

D

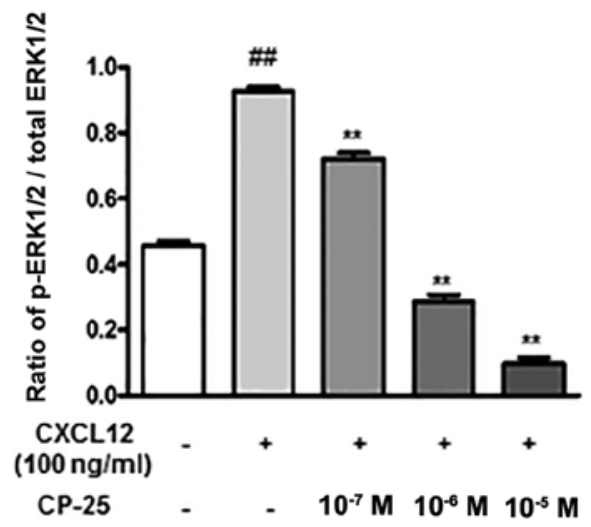

$\mathbf{E}$

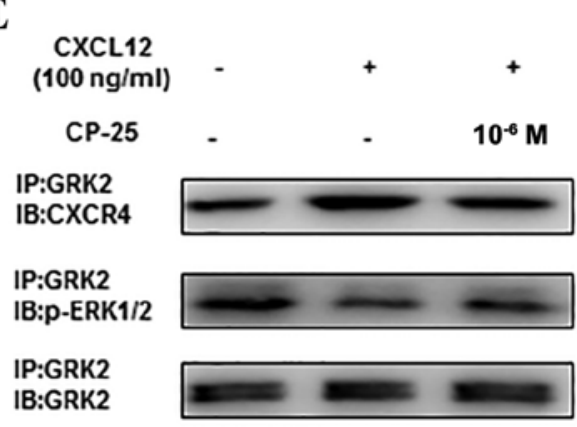

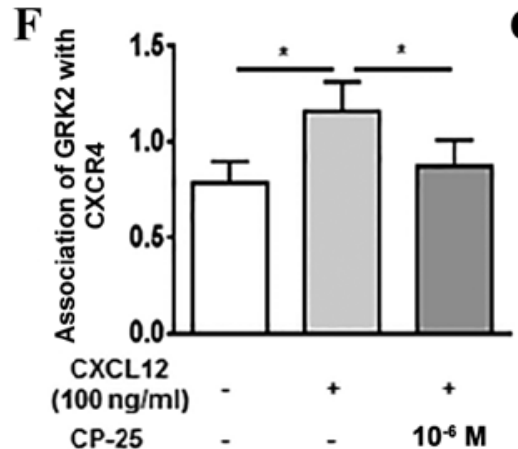

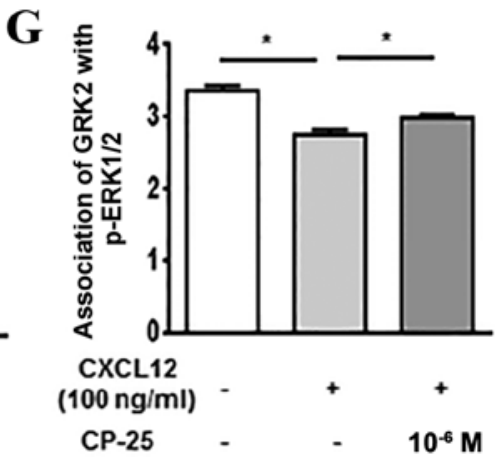

Figure 5. Effects of CP-25 on ERK1/2 expression in HUVECs treated with CXCL12. (A) Representative images of western blotting of the expression of ERK1/2 and p-ERK1/2. (B and C) Western blotting semi-quantification of ERK1/2 and p-ERK1/2. (D) Ratio of p-ERK/total-ERK. (E) Representative images of western blotting for the co-expression of GRK2 and CXCR4, and GRK2 and p-ERK1/2. (F and G) Western blotting semi-quantification of the binding between GRK2 and CXCR4, and GRK2 and p-ERK1/2. Data are expressed as the means \pm standard deviation of three independent experiments. ${ }^{\# \#} \mathrm{P}<0.01$ vs. control; ${ }^{*} \mathrm{P}<0.05,{ }^{* *} \mathrm{P}<0.01$ vs. CXCL12. CP-25, paeoniflorin-6'-O-benzene sulfonate; CXCL12, C-X-C motif chemokine ligand 12; CXCR4, C-X-C chemokine receptor type 4; GRK2; G protein-coupled receptor kinase 2; p, phosphorylated.

the CXCL12 treatment group, the expression of p-ERK1/2 and the ratio of p-ERK/ERK in CP-25-treated cells $\left(1 \times 10^{-7}, 1 \times 10^{-6}\right.$ and $1 \times 10^{-5} \mathrm{~mol} / \mathrm{l}$ ) was significantly downregulated (Fig. 5A-D). Co-immunoprecipitation and western blotting was also performed to investigate the interaction between GRK2 and CXCR4, and between GRK2 and p-ERK1/2 in HUVECs treated with CXCL12. Following CXCL12 (100 ng/ml) cell stimulation for $30 \mathrm{~min}$ and treatment with CP-25 (1x10-6 $\mathrm{mol} / \mathrm{l})$ for $24 \mathrm{~h}$, the results demonstrated that CXCL12 increased the interaction between GRK2 and CXCR4, and downregulated the interaction between GRK2 and p-ERK1/2. Conversely, $\mathrm{CP}-25$ could downregulate the interaction between GRK2 and CXCR4, and upregulate the interaction between GRK2 and p-ERK1/2 (Fig. 5E-G).

\section{Discussion}

The present study investigated the anti-angiogenic activity of $\mathrm{CP}-25$, which is a novel ester derivative of Pae. The results from this study suggested that treatment with CP-25 may inhibit the biological function of endothelial cells that contribute to the progression of autoimmune arthritis by reducing synovial angiogenesis.

The rat model of AA has been used in numerous studies to elucidate the pathogenesis of RA and to determine potential therapeutic targets. The arthritic etiology of AA and RA exhibits similar pathological and immunological features, including immune dysfunction, synoviocyte proliferation and pannus formation $(3,32)$. In RA, pannus formation corresponds 

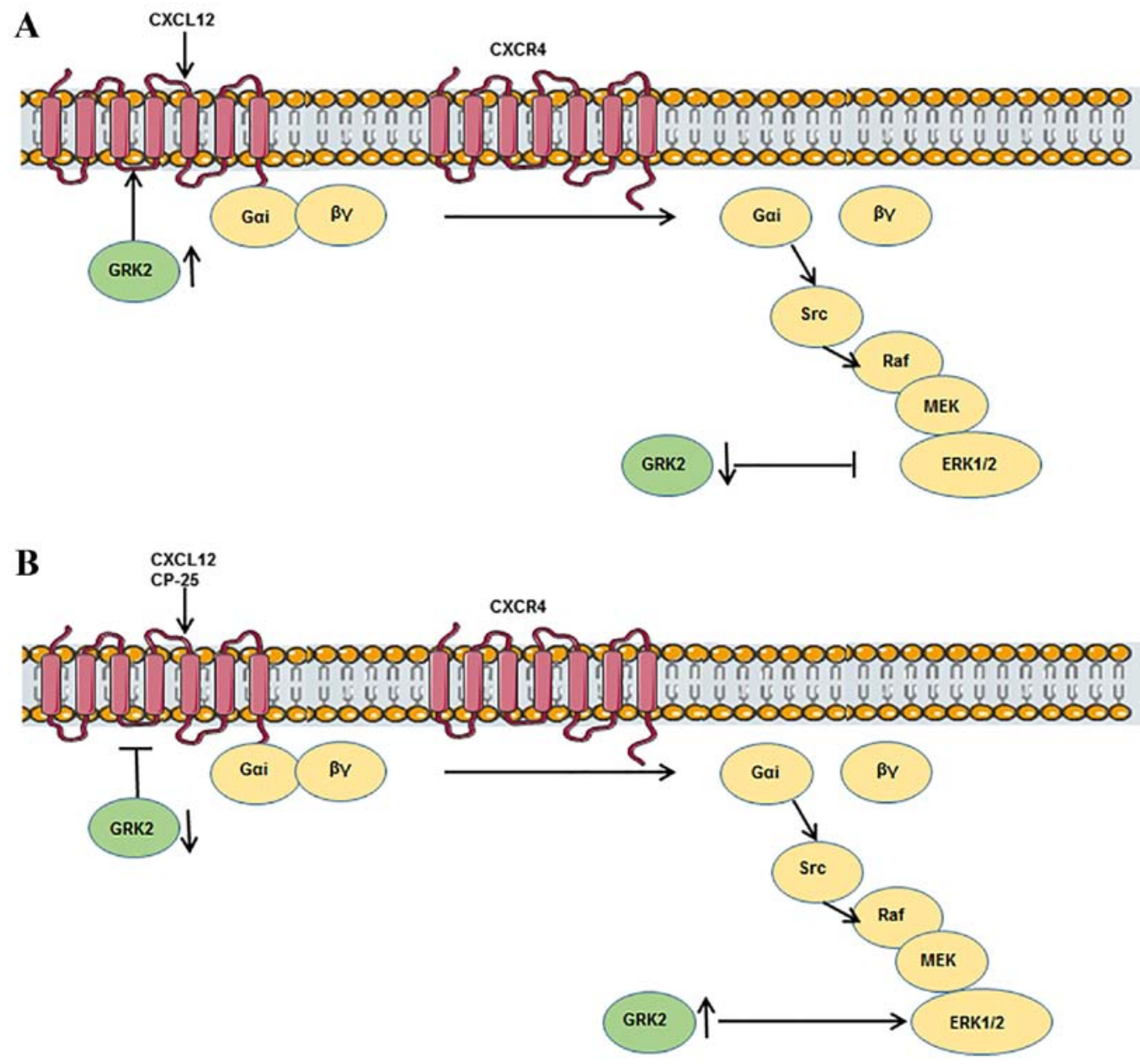

Figure 6. Regulation of CXCR4 activity and signaling. (A) Upon ligand binding, CXCR4 could activate numerous signaling cascades, which may result in increased GRK2 membrane localization, weakening the inhibitory effect of GRK2 on ERK1/2 in the cytoplasm and enhancing ERK1/2 phosphorylation. (B) CP-25 could inhibit ERK1/2 phosphorylation by reducing the membrane localization of GRK2 and enhancing the inhibitory effect of GRK2 on ERK1/2 in the cytoplasm. CP-25, paeoniflorin-6'-O-benzene sulfonate; CXCL12, C-X-C motif chemokine ligand 12; CXCR4, C-X-C chemokine receptor type 4; GRK2; G protein-coupled receptor kinase 2; p, phosphorylated.

to an invasive and destructive front of inflammatory vascular tissue that covers and erodes articular cartilage, subchondral bone and peri-articular soft tissues. Therapeutic options aiming to suppress angiogenesis may therefore represent a useful strategy for preventing RA progression. CP-25 has a clear therapeutic effect in AA, and our previous studies demonstrated that it inhibits synovial and immune cell functions $(26,35)$. However, the anti-angiogenic effects and underlying mechanism of CP-25 remain unclear. In the present study, CP-25 treatment significantly attenuated the clinical features of AA, synovial proliferation, and inflammatory and pannus scores in vivo. Furthermore, there was a positive correlation between pannus score and the expression of CXCL12 and CXCR4 in the synovium.

Endothelial cells serve a crucial role in angiogenesis. The effect of CP-25 on endothelial cell function and CXCL12/CXCR4 signaling was therefore examined using HUVECs. Synovial angiogenesis and pannus formation may represent specific features that make RA difficult to cure. Circulating pro-angiogenic factors are commonly increased in patients with RA, and the joint microenvironment is frequently characterized by low oxygen levels and numerous inflammatory factors and active pro-angiogenic molecules (36). A previous study reported that CXCL12 levels in the synovium of patients with RA treated with golimumab are correlated with disease activity, and that CXCR4 is associated with joint degeneration (14). Notably, small molecules acting as CXCR4 antagonists have exhibited promising outcomes in animal models of arthritis (37); for example, AMD3100, which is a CXCR4 antagonist, inhibits CIA in interferon- $\gamma$-deficient mice (38).

In the present study, HUVECs were used to explore the effects and underlying mechanisms of CP-25 on angiogenesis. Currently, CXCL12 is considered to have significant effects on promoting angiogenesis in RA and certain types of cancer $(39,40)$. As demonstrated in the present study, high levels of CXCL12 (50, 100 and $200 \mathrm{ng} / \mathrm{ml})$ significantly promoted the proliferation, migration and tube formation of HUVECs. Furthermore, CP-25 significantly inhibited CXCL12-induced cell proliferation, migration and tube formation, in a dose-dependent manner, which suggested that CXCL12 may have a crucial role in HUVEC functions, and that CP-25 may inhibit these functions.

GRK2, a member of the serine/threonine protein kinases family, can specifically recognize and phosphorylate agonist-activated G protein-coupled receptors (GPCRs), and 
is emerging as a key integrative node in various signaling pathways (41). The expression and activity of GRK2 may be important in the pathophysiology of RA (20). A previous study reported that GRK2 exerts some effects on cell chemotaxis due to its ability to trigger desensitization or internalization of specific chemokine receptors (42). Our previous study also demonstrated that paroxetine, which is a GRK2 antagonist, can attenuate the symptoms of rats with CIA (43). GRK2, a labile protein ordinarily degraded via the ubiquitin/proteasome pathway, can be phosphorylated by numerous kinases, including ERK1/2 and MAPK $(43,44)$. CXCL12 binds to CXCR4 to activate downstream signaling pathways, including phosphoinositide 3-kinase-protein kinase B, phospholipase C-protein kinase $\mathrm{C}$ and Raf-MAPK kinase-ERK1/2, which increase cell chemotaxis and proliferation ability (45). Arrestin proteins can bind and regulate GPCR cell-surface expression, often functioning together with GRK2. Furthermore, GRK2 overexpression enhances CXCR4 internalization and inhibits the function of CXCL12 (46). In addition, ERK1/2 activation is reduced by GRK2 in the cytoplasm, which may inhibit the proliferation of endothelial cells induced by CXCL12 (47). In the present study, the interaction between CXCR4 and GRK2 in HUVECs treated with CXCL12 and CP-25 was examined in order to investigate the mechanisms underlying the effects of CP-25 on HUVECs. The results demonstrated that CXCL12 significantly promoted the proliferation, migration and tube formation of HUVECs. In addition, CXCL12 (100 ng/ml) upregulated the expression of total GRK2, membrane GRK2, cytoplasmic CXCR4 and p-ERK1/2, downregulated the expression of cytoplasmic GRK2 and membrane CXCR4, but had no effect on the expression of total CXCR4 and ERK1/2. Furthermore, CXCL12 (100 ng/ml) upregulated the interaction between GRK2 and CXCR4, and downregulated GRK2 and p-ERK1/2 interaction. Following CP-25 administration, this trend induced by CXCL12 was reversed, which indicated that CXCL12 could improve HUVECs function by increasing the membrane localization of GRK2, weakening the inhibitory effect of GRK2 on ERK1/2 in the cytoplasm, and stimulating ERK1/2 phosphorylation (Fig. 6A). In addition, $\mathrm{CP}-25$ regulated HUVECs function by reducing the membrane localization of GRK2, enhancing the inhibitory effect of GRK2 on ERK1/2 in the cytoplasm, and reducing ERK1/2 activation to alter HUVECs function (Fig. 6B). Unfortunately, this study did not analyze the $\beta$-arrestins, which may affect the internalization of CXCR4 (48). This was one limitation in the present study; however, our group is currently studying the translocation of $\beta$-arrestins and their role in regulating CXCR4 function.

In conclusion, CP-25 markedly inhibited pannus formation in a rat model of AA. The results suggested that upregulation of CXCL12 and its receptor CXCR4 may be associated with synovial inflammatory lesions and angiogenesis in AA rats. Furthermore, the therapeutic effects of CP-25 on AA may be related to inhibition of angiogenesis. CP-25 inhibited GRK2 transfer from the cytoplasm to the membrane, thus restoring cytoplasmic GRK2 expression, which may inhibit the activation of ERK; this is the potential mechanism underlying the inhibitory effects of CP-25 on proliferation, migration and tube-forming ability of HUVECs. The findings from the present study provided a potential novel mechanism for the anti-angiogenic activity of CP-25 in the treatment of RA. However, in order to increase our understanding of the anti-inflammatory and immunomodulatory effects of CP-25 in RA, further investigation is required at clinical and molecular levels.

\section{Acknowledgements}

The authors would like to thank Dr Li Gui and Dr Dake Huang (Synthetic Laboratory of Anhui Medical University) for their technical assistance.

\section{Funding}

This study was supported by the National Natural Science Foundation of China (grant nos. 81330081 and 81503084).

\section{Availability of data and materials}

All data generated or analyzed during this study are included in this published article.

\section{Authors' contributions}

MZ, LS and WW conceived the original idea and planned the experiments. MZ, MG and JC participated in the experiments. All authors analyzed and interpreted the data. MZ wrote the manuscript with the support of LS and WW. All authors approved the final version of the manuscript.

\section{Ethics approval and consent to participate}

All experiments were approved by the Ethics Review Committee for Animal Experimentation of the Institute of Clinical Pharmacology, Anhui Medical University. All experiments were conducted according to the animal care and use committee guidelines.

\section{Patient consent for publication}

Not applicable.

\section{Competing interests}

The authors declare that they have no competing interests.

\section{References}

1. Bottini N and Firestein GS: Duality of fibroblast-like synoviocytes in RA: Passive responders and imprinted aggressors. Nat Rev Rheumatol 9: 24-33, 2013.

2. McInnes IB and Schett G: The pathogenesis of rheumatoid arthritis. N Engl J Med 365: 2205-2219, 2011.

3. Choudhary N, Bhatt LK and Prabhavalkar KS: Experimental animal models for rheumatoid arthritis. Immunopharmacol Immunotoxicol 40: 193-200, 2018

4. Elshabrawy HA, Chen Z, Volin MV, Ravella S, Virupannavar S and Shahrara S: The pathogenic role of angiogenesis in rheumatoid arthritis. Angiogenesis 18: 433-448, 2015.

5. Szekanecz Z and Koch AE: Vascular involvement in rheumatic diseases: 'Vascular rheumatology'. Arthritis Res Ther 10: 224, 2008.

6. Lainer-Carr D and Brahn E: Angiogenesis inhibition as a therapeutic approach for inflammatory synovitis. Nat Clin Pract Rheumatol 3: 434-442, 2007

7. Komatsu N and Takayanagi $\mathrm{H}$ : Bone and cartilage destruction in rheumatoid arthritis. Clin Calcium 22: 179-185, 2012 (In Japanese). 
8. Kawaguchi N,Zhang TT and Nakanishi T: Involvement of CXCR4 in normal and abnormal development. Cells 8: E185, 2019.

9. Orimo A,Gupta PB, SgroiDC, Arenzana-Seisdedos F, DelaunayT, Naeem R, Carey VJ, Richardson AL and Weinberg RA: Stromal fibroblasts present in invasive human breast carcinomas promote tumor growth and angiogenesis through elevated SDF-1/CXCL12 secretion. Cell 121: 335-348, 2005.

10. Patrussi L and Baldari CT: The CXCL12/CXCR4 axis as a therapeutic target in cancer and HIV-1 infection. Curr Med Chem 18: 497-512, 2011.

11. Pablos JL, Santiago B, Galindo M, Torres C, Brehmer MT, Blanco FJ and García-Lázaro FJ: Synoviocyte-derived CXCL12 is displayed on endothelium and induces angiogenesis in rheumatoid arthritis. J Immunol 170: 2147-2152, 2003

12. Tachibana K, HirotaS, Iizasa H, Yoshida H, Kawabata K, Kataoka Y, Kitamura Y, Matsushima K, Yoshida N, Nishikawa S, et al: The chemokine receptor CXCR4 is essential for vascularization of the gastrointestinal tract. Nature 393: 591-594, 1998.

13. Blades MC, Ingegnoli F, Wheller SK, Manzo A, Wahid S, Panayi GS, Perretti M and Pitzalis C: Stromal cell-derived factor 1 (CXCL12) induces monocyte migration into human synovium transplanted onto SCID Mice. Arthritis Rheum 46: 824-836, 2002

14. Kanbe K, Chiba J, Inoue Y, Taguchi M and Yabuki A: SDF-1 and CXCR4 in synovium are associated with disease activity and bone and joint destruction in patients with rheumatoid arthritis treated with golimumab. Mod Rheumatol 26: 46-50, 2016.

15. Zhang F, Shu JL, Li Y, Wu YJ, Zhang XZ, Han L, Tang XY, Wang C, Wang QT, Chen JY, et al: CP-25, a novel anti-inflammatory and immunomodulatory drug, inhibits the functions of activated human $B$ cells through regulating BAFF and TNF- $\alpha$ signaling and comparative efficacy with biological agents. Front Pharmacol 8: 933, 2017.

16. Jia XY, Chang Y, Sun XJ, Wu HX, Wang C, Xu HM, Zhang L, Zhang LL, Zheng YQ, Song LH, et al: Total glucosides of paeony inhibit the proliferation of fibroblast-like synoviocytes through the regulation of $\mathrm{G}$ proteins in rats with collagen-induced arthritis. Int Immunopharmacol 18: 1-6, 2014.

17. Wu H, Wei W, Song L, Zhang L, Chen Y and Hu X: Paeoniflorin induced immune tolerance of mesenteric lymph nodelymphocytes via enhancing beta 2-adrenergic receptor desensitization in rats with adjuvant arthritis. Int Immunopharmacol 7: 662-673, 2007.

18. Wang QT, Zhang LL, Wu HX and Wei W: The expression change of $\beta$-arrestins in fibroblast-like synoviocytes from rats with collagen-induced arthritis and the effect of total glucosides of paeony. J Ethnopharmacol 133: 511-516, 2011.

19. Wang C, Yuan J, Wu HX, Chang Y, Wang QT, Wu YJ, Liu LH and Wei W: Paeoniflorin inhibits inflammatory responses in mice with allergic contact dermatitis by regulating the balance between inflammatory and anti-inflammatory cytokines. Inflamm Res 62: 1035-1044, 2013.

20. Zhang LL, Wei W, Wang NP, Wang QT, Chen JY, Chen Y, $\mathrm{Wu} \mathrm{H}$ and $\mathrm{Hu} \mathrm{XY}$ : Paeoniflorin suppresses inflammatory mediator production and regulates $\mathrm{G}$ protein-coupled signaling in fibroblast-like synoviocytes of collagen induced arthritic rats. Inflamm Res 57: 388-395, 2008.

21. Chen JY, Wu HX, Chen Y, Zhang LL, Wang QT, Sun WY and Wei W: Paeoniflorin inhibits proliferation of fibroblast-like synoviocytes through suppressing G-protein-coupled receptor kinase 2. Planta Med 78: 665-671, 2012

22. Chang Y, Zhang L, Wang C, Jia XY and Wei W: Paeoniflorin inhibits function of synoviocytes pretreated by rIL-1 $\alpha$ and regulates EP4 receptor expression. J Ethnopharmacol 137: 1275-1282, 2011.

23. Chang Y, Wei W, Zhang L and Xu HM: Effects and mechanisms of total glucosides of paeony on synoviocytes activities in rat collagen-induced arthritis. J Ethnopharmacol 121: 43-48, 2009.

24. Liu ZQ, Jiang ZH, Liu L and $\mathrm{Hu}$ M: Mechanisms responsible for poor oral bioavailability of paeoniflorin: Role of intestinal disposition and interactions with sinomenine. Pharm Res 23 2768-2780, 2006.

25. Wang C, Yuan J, Yang ZY, Nie XX, Song LH and Wei W: Pharmacokinetics of paeoniflorin microemulsion after repeated dosing in rats with adjuvant arthritis. Pharmazie 67: 997-1001, 2012.

26. Wang C, Yuan J, Zhang LL and Wei W: Pharmacokinetic comparisons of Paeoniflorin and Paeoniflorin-6'O-benzene sulfonate in rats via different routes of administration. Xenobiotica 46: 1142-1150, 2016

27. Yang XD, Wang C, Zhou P, Yu J, Asenso J, Ma Y and Wei W: Absorption characteristic of paeoniflorin-6'-O-benzene sulfonate $(\mathrm{CP}-25)$ in in situ single-pass intestinal perfusion in rats. Xenobiotica 46: 775-783, 2016.
28. Chang Y, Jia X, Wei F, Wang C, Sun X, Xu S, Yang X, Zhao Y, Chen J, Wu H, et al: CP-25, a novel compound, protects against autoimmune arthritis by modulating immune mediators of inflammation and bone damage. Sci Rep 6: 26239, 2016

29. Jia X, Wei F, Sun X, Chang Y, Xu S, Yang X, Wang C and Wei W: $\mathrm{CP}-25$ attenuates the inflammatory response of fibroblast-like synoviocytes co-cultured with BAFF-activated CD4(+) T cells. J Ethnopharmacol 189: 194-201, 2016.

30. Sun WY, Wu JJ, Peng WT, Sun JC and Wei W: The role of $\mathrm{G}$ protein-coupled receptor kinases in the pathology of malignant tumors. Acta Pharmacol Sin 39: 1699-1705, 2018.

31. Premont RT and Gainetdinov RR: Physiological roles of $\mathrm{G}$ protein-coupled receptor kinases and arrestins. Annu Rev Physiol 69: 511-534, 2007.

32. Métayé $\mathrm{T}$, Gibelin $\mathrm{H}$, Perdrisot $\mathrm{R}$ and Kraimps JL: Pathophysiological roles of G-protein-coupled receptor kinases. Cell Signal 17: 917-928, 2005.

33. Yu H, Yang YH, Rajaiah R and Moudgil KD: Nicotine-induced differential modulation of autoimmune arthritis in the Lewis rat involves changes in interleukin-17 and anti-cyclic citrullinated peptide antibodies. Arthritis Rheum 63: 981-991, 2011.

34. Chen J, Wang Q, Wu H, Liu K, Wu Y, Chang Y and Wei W: The ginsenoside metabolite compound $\mathrm{K}$ exerts its anti-inflammatory activity by downregulating memory B cell in adjuvant-induced arthritis. Pharm Biol 54: 1280-1288, 2016

35. Wang Y, Han CC, Cui D, Luo TT, Li Y, Zhang Y, Ma Y and Wei W: Immunomodulatory Effects of CP-25 on splenic T cells of rats with adjuvant arthritis. Inflammation 41: 1049-1063, 2018

36. Semerano L, Clavel G, Assier E, Denys A and Boissier MC: Blood vessels, a potential therapeutic target in rheumatoid arthritis? Joint Bone Spine 78: 118-123, 2011.

37. Khan A, Greenman J and Archibald SJ: Small molecule CXCR4 chemokine receptor antagonists: Developing drug candidates. Curr Med Chem 14: 2257-2277, 2007.

38. Hatse S, Princen K, Bridger G, De Clercq E and Schols D: Chemokine receptor inhibition by AMD3100 is strictly confined to CXCR4. FEBS Lett 527: 255-262, 2002.

39. Matsuo Y, Ochi N, Sawai H, Yasuda A, Takahashi H, Funahashi H, Takeyama H, Tong Z and Guha S: CXCL8/IL-8 and CXCL12/ SDF-1alpha co-operatively promote invasiveness and angiogenesis in pancreatic cancer. Int J Cancer 124: 853-861, 2009.

40. Salcedo R, Wasserman K, Young HA, Grimm MC, Howard OM, Anver MR, Kleinman HK, Murphy WJ and Oppenheim JJ: Vascular endothelial growth factor and basic fibroblast growth factor induce expression of CXCR4 on human endothelial cells: In vivo neovascularization induced by stromal-derived factor-1alpha. Am J Pathol 154: 1125-1135, 1999.

41. Gurevich EV, Tesmer JJ, Mushegian A and Gurevich VV: $G$ protein-coupled receptor kinases: More than just kinases and not only for GPCRs. Pharmacol Ther 133: 40-69, 2012.

42. Brondello JM, Pouysségur J and McKenzie FR: Reduced MAP kinase phosphatase-1 degradation afterp42/p44MAPK-dependent phosphorylation. Science 286: 2514-2517, 1999.

43. Wang Q, Wang L, Wu L, Zhang M, Hu S, Wang R, Han Y, Wu Y, Zhang $\mathrm{L}$, Wang $\mathrm{X}$, et al: Paroxetine alleviates $\mathrm{T}$ lymphocyte activation and infiltration to joints of collagen-induced arthritis. Sci Rep 7: 45364, 2017.

44. Penela P,Ruiz-Gómez A, Castaño JG and Mayor F Jr: Degradation of the $\mathrm{G}$ protein-coupled receptor kinase 2 by the proteasome pathway. J Biol Chem 273: 35238-35244, 1998

45. Woodard LE and Nimmagadda S: CXCR4-based imaging agents. J Nucl Med 52: 1665-1669, 2011.

46. Clift IC, Bamidele AO, Rodriguez-Ramirez C, Kremer KN and Hedin KE: $\beta$-Arrestin1 and distinct CXCR4 structures are required for stromal derived factor- 1 to downregulate CXCR4 cell-surface levels in neuroblastoma. Mol Pharmacol 85: 542-552, 2014.

47. Busillo JM, Armando S, Sengupta R, Meucci O, Bouvier M and Benovic JL: Site-specific phosphorylation of CXCR4 is dynamically regulated by multiple kinases and results in differential modulation of CXCR4 signaling. J Biol Chem 285: 7805-7817, 2010.

48. Cheng ZJ, Zhao J, Sun Y, Hu W, Wu YL, Cen B, Wu GX and Pei G: $\beta$-arrestin differentially regulates the chemokine receptor CXCR4-mediated signaling and receptor internalization, and this implicates multiple interaction sites between $\beta$-arrestin and CXCR4. J Biol Chem 275: 2479-2485, 2000.

This work is licensed under a Creative Commons Attribution-NonCommercial-NoDerivatives 4.0 International (CC BY-NC-ND 4.0) License. 